\title{
A Hybrid Framework to Assess the Risk of Change in Construction Projects Using Fuzzy Fault Tree and Fuzzy Event Tree Analysis
}

\begin{abstract}
Change is known as a common risk in construction projects that have adverse impact on project performance. Thus, proactive change management in construction project plays a significant role in project successful completion by investigating potential changes and their probable consequences on project objectives. The focus of this study is to develop a hybrid framework to proactively manage change by evaluating change formation and implementation phases. In the proposed framework, first, the fuzzy fault tree is used to identify the root causes of change and estimate the change occurrence probability. Then, the fuzzy event tree analysis is employed to foresee the possible scenarios that may arise from a change and assess the probability of occurrence and also the degree of change impact on project objectives. Considering the probability and the degree of impacts, a risk index is employed to describe risk priority level. The proposed framework enables the project team to recognize and monitor change causes and also identify change effects. Eventually, it informs the project team to identify effective risk response strategies and deal with disruptive effects of change.
\end{abstract}

Keywords: risk assessment; change management; construction projects; fault tree analysis; event tree analysis; fuzzy logic 


\section{Introduction}

Construction projects are prone to many risks and change is considered to be a major source of it (Ibrahim A. Motawa, Anumba, \& El-Hamalawi, 2006). Occurrence of Change during a project is a very common and almost inevitable problem that can result in deviations from the baseline project plan and cause time delays, cost overruns and quality defects (Sun \& Meng, 2009). In construction projects, a change is defined as any additions, deletions, or other revision to project goal, scope and pre-existing conditions, assumptions or requirements (C. W. Ibbs, Wong, \& Kwak, 2001; Sun, Fleming, Senaratne, Motawa, \& Yeoh, 2006). Change can be beneficial or detrimental (Hanna, Lotfallah, \& Lee, 2002; I. A. Motawa, Anumba, Lee, \& Peña-Mora, 2007). Since beneficial changes bring advantages to a project, these changes are welcomed in a project (Hwang \& Low, 2012). However, it is vitally important to implement tools and techniques to manage the risk of detrimental changes and reduce their destructive effects on project performance.

The aim of this study is to develop a comprehensive framework for proactive change management and assess the risk of potential changes. Proactive change management refers to dealing with change before it occurs (I. A. Motawa et al., 2007). Moreover, the focus of this study is only on changes that occur during the project construction stage and their negative impacts on the main project objectives (i.e. time, cost and quality). In order to successfully predict the change occurrence and develop a proactive action plan to deal with the risk and consequences of the change, the project team needs to implement proactive change management techniques (Ibrahim A. Motawa et al., 2006). Estimation of the likelihood of occurrence of a change event and the degree of change impacts on project parameters are prerequisites for proactive change management (Heravi \& Charkhakan, 2015; Ibrahim A. Motawa et al., 2006). Therefore, this study 
intends to develop a framework to assess change probability and impact, which finally help to assess the risk of change.

\section{Literature Review}

Previous studies related to this research can be divided into the following two categories:

1. Identification and classification of change causes and effects

The common root causes of changes and their effects in the construction projects have been investigated in several studies. Wu, Hsieh, and Cheng (2005) identified and categorized the causes of design change in highway construction projects in Taiwan and developed a statistical analysis method to estimate cost variance due to a change order. Arain and Pheng (2005) identified the potential effects of change orders on institutional building projects in Singapore. The result showed delay, increase in project cost and quality degradation are the most frequent effects of change. Sun and Meng (2009) proposed two comprehensive taxonomies for the causes and effects of change by reviewing the existing literature. They considered time extension, cost increase, quality and productivity degradation to be the common change effects. Alnuaimi, Taha, Mohsin, and Al-Harthi (2010) investigated the causes and effects of change in public construction projects in Oman. In their study, the delay schedule delays, disputes, and cost overruns were identified as the most important effects of change. A study conducted by Enshassi, Arain, and Al-Raee (2010) in Gaza Strip showed that lack of materials and equipment, change in design by consultant and lack of consultant's knowledge of available materials are the top three most important causes of change orders. A similar study on change orders in Kuwait construction projects showed that change of plans or project scope by owner, problems on site, and errors and omission in design are the most frequent causes of change (Alaryan, Emadelbeltagi, Elshahat, \& Dawood, 2014). Increase in cost of the project, delay in completion of schedule, and increase in the duration of individual activities 
are also identified as the most common effects of change orders. Memon, Abdul Rahman, and Faris Abul Hasan (2014) used a questionnaire survey to identify the causes and effects of change in construction projects. The study concluded that the main causes of change orders are unavailability of equipment, poor workmanship and complexity of design and the most important effect of change orders is on project cost and time. Shrestha and Maharjan (2018) studied the effects of change orders in highway projects in Texas and found that change order has a significant impact on cost and schedule growth and it also increases the speed of construction.

2. Systems and models for proactive change management

A fuzzy model was proposed by (Ibrahim A. Motawa et al. (2006)) that stimulates the relationships between project characteristics and the causes and effects of change and estimates the likelihood of occurrence of a change event and evaluates its impact on project parameters. Arain and Pheng (2007) presented a knowledge-based decision-support system for proactive change management. I. A. Motawa et al. (2007) developed an integrated system for change management system. The system combines a fuzzy logic-based change prediction model with the system dynamics model of the dynamic planning and control methodology to predict change events and estimate its negative effects on project performance. A k-nearest neighbor based knowledge-sharing model developed by Chen (2008) that will help the interested parties to avoid litigious disputes triggered by change orders. Zhao, Lv, Zuo, and Zillante (2010) used activity-based dependency structure matrix method to develop a change management system. This system models the relationship between project activities and predicts the effect of a change in an activity on project schedule. Charkhakan and Heravi (2012) used dynamic programming method to present a model that identifies different change formation scenarios by monitoring and analyzing change occurrence paths. To promote their previous model, they proposed a framework for predicting and tracing 
change formation scenarios. They proposed decision-making trial and evaluation laboratory to analyze change formation paths and estimate the relative importance of change formation components, the probability of occurrence and the traceability of the change formation scenarios (Heravi \& Charkhakan, 2014). Later, the authors employed the event tree analysis to evaluate change implementation phase and predict the likelihood of occurrence of change and arising conflicts and litigation due to a change order (Heravi \& Charkhakan, 2015). Based on empirical formulation, W. Ibbs and Chen (2015) proposed a multivariate change-predictive tool. For quantitative change prediction, this tool uses a linear model that represents the amount of change as the percentage in the baseline budget. Moreover, they used clustering and classification tree models for qualitative prediction, with which change level in a project can be measured relatively against the overall performance in the industry. Likhitruangsilp, Handayani Tantri, Ioannou Photios, and Yabuki (2018) introduced a BIM-based decision support system which can be used to predict the impact of a change order on project time, cost and physical conditions. Ansari (2019) developed a comprehensive Dynamic Simulation Model for proactive change management. The system dynamics approach was utilized to analyze the effect of a change order on the baseline plan of project in terms of time, cost, quality and resources. In 2019, a framework introduced by Abad, Eshtehardian, and Taghizade (2019) to assess the risk of change by employing fuzzy fault tree analysis. This study is dedicated to change formation process and introduced a risk index that can utilized to evaluate the impact of change on project objectives.

Although proactive change management has been the focus of many research, the literature review revealed that little attention has been devoted to develop an integrated framework that addresses both change formation and implementation phases. Besides, very few studies approached change as a risk event and there has been little investigation on assessing the risk value of change. Since 
change is a risk event (Abad et al., 2019; Ibrahim A. Motawa et al., 2006), there is a gap for research on the benefits of employing risk analysis tools and techniques for proactive change management. To address these limitations, the current study aims to integrate the areas of risk management and change management to develop a hybrid framework for proactive change management in construction projects. This study expands the framework proposed by (Abad et al., 2019) into a comprehensive hybrid framework to investigate the change formation and implementation phases and estimates the change probability and impact on project objectives. This proactive method enables the project team to manage change occurrence and its detrimental effects more effectively.

\section{Methodology}

In order to deal with the complexity of managing change in construction projects, it is necessary to analyze change formation and change implementation processes. Change formation process is the initial phase of change occurrence that results in a change request. Change implementation process follows the change request approval, and it is when a change is being applied in a project. This research proposes a hybrid framework based on fuzzy logic that combines fault tree analysis (FTA) and event tree analysis (ETA) to assess the risk of change which refers to the possibility of change occurrence and its consequences. FTA is a graphical demonstration of the root causes of an undesirable event and their logical interrelationship. In this framework, FTA is used as a proactive method to identify and analyze the root causes of a change. It helps to understand change formation process by breaking down a potential change into its root causes. Moreover, because of its operational simplicity it is a useful tool to predict the probability of change occurrence. ETA is a logic tree diagram that starts from with a particular initiating event and depicts the chains of subsequent events that propagates from it. This method provides an understanding of the 
consequences of a risk event and determining the final outcome of the event. Furthermore, using ETA method, the probability of occurrence of final outcomes can be estimated. Here, ETA is utilized to evaluate the change implementation process and the change impact on project objectives. To ease the need of historical data and facilitate the application of FTA and ETA in construction industry, this study combines fuzzy logic with FTA and ETA techniques.

Before introducing the proposed framework in detail, we briefly review FTA and ETA and how these methods are working using fuzzy logic.

\section{Fault Tree Analysis}

FTA was first developed in 1961 by Watson of Bell Labs in collaboration with Mearns to evaluate the Minuteman launch control system for the US Air Force (Ericson, 1999). Since then, FTA has been used by many industries and technologies for safety, reliability and risk analysis. FTA is a diagrammatic and deductive technique to understand the sequence of events that could lead to a top event (TE). It is also a useful tool to calculate the probability of the TE occurrence.

To develop a fault tree structure, first the immediate causes of the TE must be identified. These immediate causes are referred to as gate events (GEs). The analysis continues by decomposing GEs into their immediate causes, which can be other GEs or basic events (BEs). Fault tree ends with identifying BEs. BEs are the primary causes of the TE and are located at the lowest level of each branch of a fault tree and cannot be further developed. Then, AND and OR gates are used to show the type of logical relationship of lower events that lead to the occurrence of an upper event. The AND gate shows that the upper events occur only if all of the lower events occur. In terms of probability, the AND gate represents the intersection of the events $(\cap)$ and is equivalent to the

Boolean symbol “.”. The OR gate is equivalent to the operation of union (U) or Boolean symbol 
"+", and means the occurrence of one of the lower events is enough for the upper event to take place (NASA, 2002).

Fault tree can be employed in both qualitative and quantitative analysis. Qualitative analysis is applying Boolean algebra to obtain minimal cut sets (MCSs). A MCS as is the smallest combination of BEs that result in a TE (NASA, 2002). In other words, MCS represents the TE in terms of the basic events. To illustrate the fault tree qualitative analysis, consider the fault tree structure shown in Fig. 1. By applying Boolean algebra rules the MCSs of the tree are obtained as shown in Eqs. 1 to 4.

$$
\begin{gathered}
T E=G E_{1} \cup G E_{2} \\
G E_{1}=B E_{1} \cap B E_{2} \\
G E_{2}=B E_{2} \cup B E_{3} \\
T E=\left(B E_{1} \cap B E_{2}\right) \cup B E_{2} \cup B E_{3} \\
M C S_{1}=\left(B E_{1} \cap B E_{2}\right), M C S_{2}=B E_{2}, M C S_{3}=B E_{3}
\end{gathered}
$$

Eq. 4 shows that the fault tree has three minimal cut sets $\left(B E_{1} \cap B E_{2}\right), B E_{2}$ and $B E_{3}$. The occurrence of $B E_{1}$ and $B E_{2}$ at the same time will cause the TE to occur, while $B E_{2}$ and $B E_{3}$ are sufficient by themselves to cause the TE to occur. 


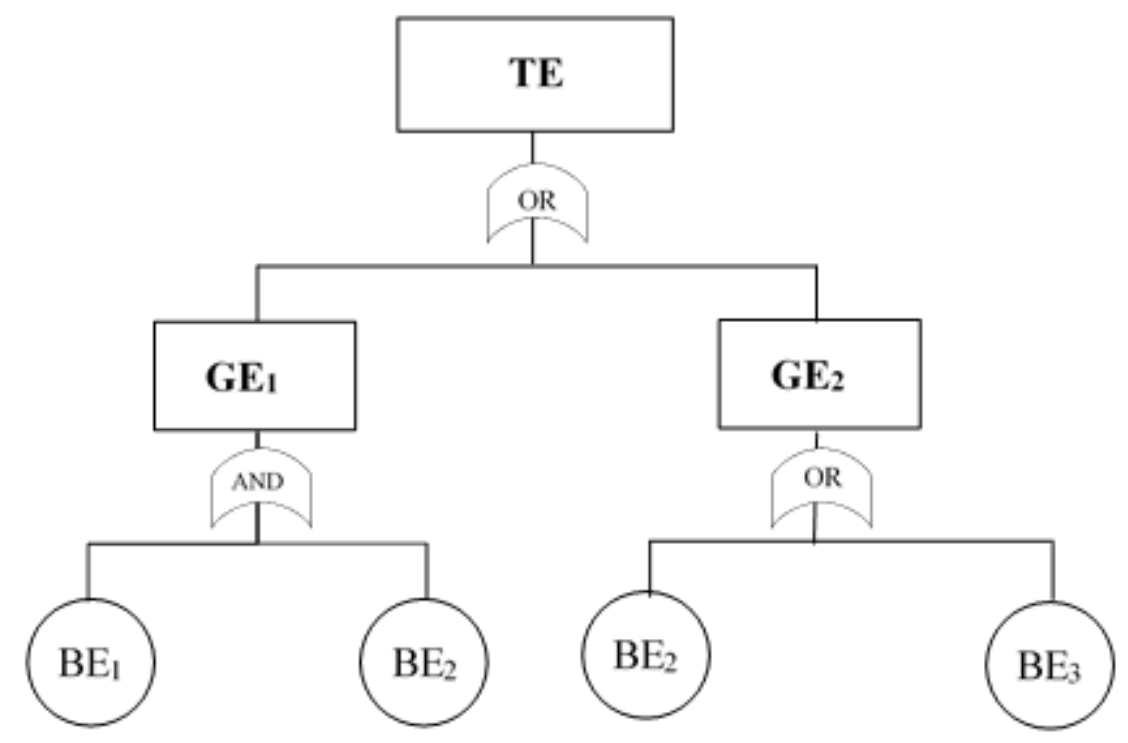

Fig. 1. Example of fault tree structure

After determining the MCSs, quantitative analysis can be conducted to calculate the probability of occurrence of TE (i.e. $P(T E)$ ). In order to quantify a fault tree, the probability of BEs occurrence must be defined. Thereafter, using Boolean algebra rules, the probabilities of MCSs and TE can be calculated.

As mentioned before to address the goals of this study, FTA is employed to evaluate the change formation process by breaking down a change into its root causes. Furthermore, FTA is a useful technique to estimate the probability of a change occurrence.

\section{Event Tree Analysis}

ETA is an inductive and diagrammatic technique to evaluate the probable consequences of an initiating event. ETA can be qualitative or quantitative. Qualitative analysis of an event tree is the identification of probabilistic events that sequentially propagated from a specific event and finishes with the end-consequences or final outcomes of the initiating event (Lees, 2005). Developing the event tree structure starts with the initial event placed on the left and continues with identifying 
the consequences that are drawn to the right as tree branches. Each branch of a tree consists of a probable consequence of the initiating event and it is connected to the next branch, which is another subsequent event resulted from the previous one. A chain of interdependent events that start with the initiating event and ends in an outcome, constitutes a path. Events located in a path are called pivotal events (PEs) (Nývlt \& Rausand, 2012). Each path in the event tree results in a specific outcome that we are interested to analyze the probability of its occurrence. Quantitative analysis of an event tree estimates the likelihood of occurrence of a path by multiplying the probability of occurrence of all PEs located in the path (Hong, Lee, Shin, Nam, \& Kong, 2009). To quantify an event tree, the probability of occurrence of the initiating event (i.e. $P\left(P E_{0}\right)$ ) is required. By integrating the ETA with FTA, the probability of PE0 can be obtained by identifying and analyzing the possible root causes of the initial event using FTA. In this way, a fault tree diagram is constructed for $\mathrm{PE}_{0}$ and the quantitative FTA is performed. The output of a quantitative FTA, which is the calculated probability of the $\mathrm{PE}_{0}$, is used as the input to conduct quantitative ETA (Andrews \& Dunnett, 2000). In a conventional event tree, the probability of occurrence of each 
path, which is the probability of the outcome, is calculated by the multiplication of the probability

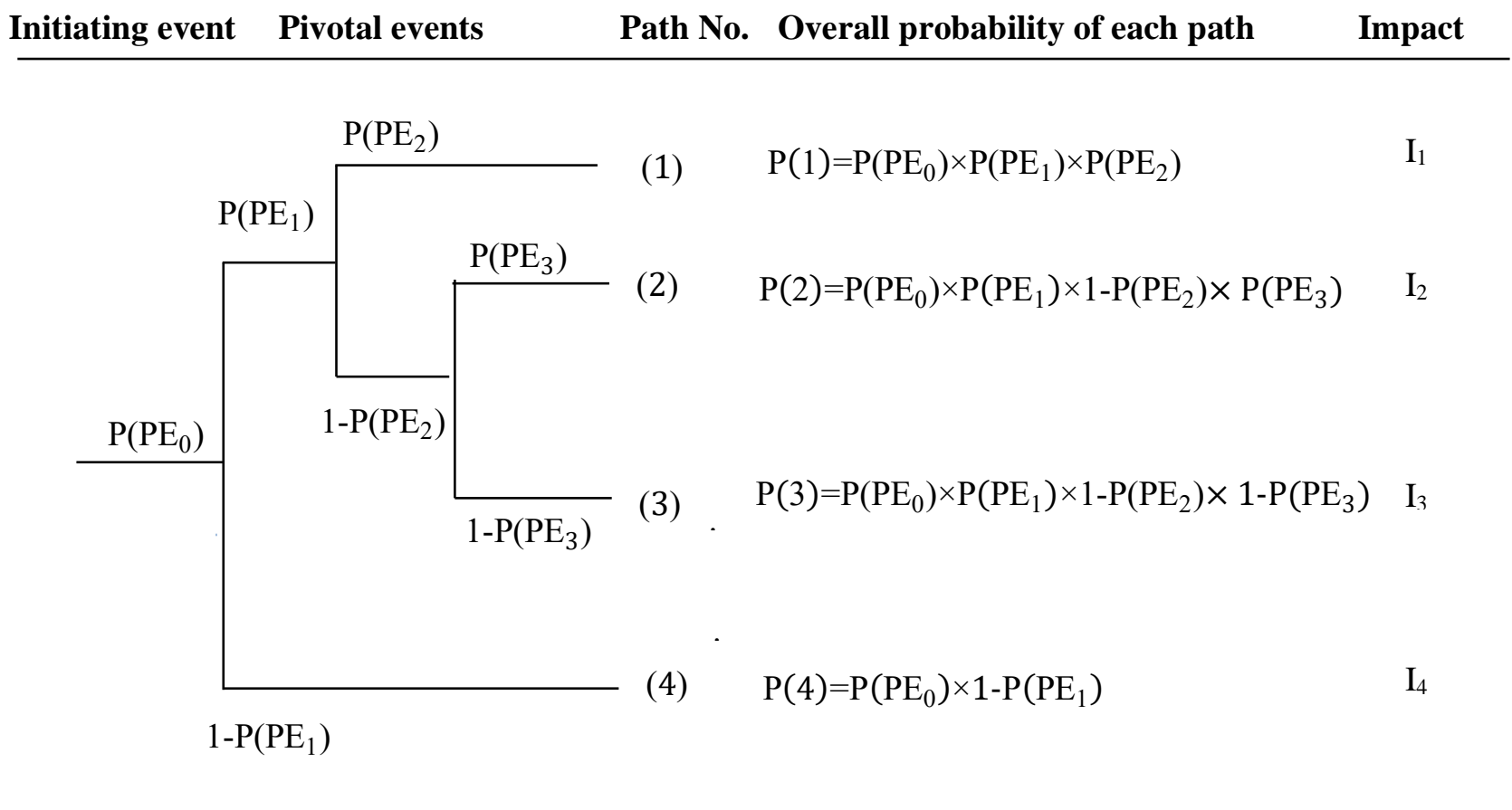

of all events in the path. Fig. 2. Shows a simple event tree structure and its quantitative analysis

Fig. 2. Example of event tree analysis

In this study, ETA is used to predict the consequences of implementation of a potential change order and assess the probability of occurrence of different outcomes due to different change implementation scenarios. Each path in the change event tree is regarded as a scenario.

\section{Fuzzy fault tree and event tree analysis}

Conventional quantitative FTA and ETA requires crisp probabilities of events. However, having access to such exact values is not always possible in the construction industry as the historical data on the probability of the causes or the consequences of change are unavailable, or incomplete and imprecise. Thus, Quantifying FTA and ETA leads to an approximation of the probability of the 
occurrence of events. This adds further uncertainty to the analysis and gives a false impression of precision and correctness that undermines the overall credibility of the process (Abdelgawad \& Fayek, 2011; Ferdous, Khan, Sadiq, Amyotte, \& Veitch, 2009). To address this problem, this study employs fuzzy FTA (FFTA) and fuzzy ETA (FETA). The fuzzy approach allows experts to express themselves in terms of linguistic variables instead of numerical values to assess the probability of BEs in a fault tree and PEs in an event tree.

FFTA and FETA have been used by several researchers for risk analysis. Abdelgawad and Fayek (2011) used FFTA technique to analyze the risk of horizontal directional drilling failure in a pipeline project. Wang, Zhang, and Chen (2013) applied the FFTA to evaluate the probability of a crude oil tank fire and explosion. Lavasani, Zendegani, and Celik (2015) applied FFTA method to assess the risk of fire, explosion and toxic gas releases in petrochemical industry. This method also was utilized to analyze the risk of leakage in abandoned oil and gas wells in the drilling industry (Lavasani, Ramzali, Sabzalipour, \& Akyuz, 2015). Cheliyan and Bhattacharyya (2018) used FFTA to analysis the probability of leakage of oil and gas in a subsea production system. Ramzali, Lavasani, and Ghodousi (2015) used FETA method to evaluate the impacts of safety barriers failure in offshore oil and gas drilling systems. Moreover, in a recent study, application of FFTA for evaluating the change formation process in construction projects has been introduced by Abad et al. (2019).

Here, we propose a hybrid framework to evaluate the change formation and implementation process. We employed the fuzzy approach to, first, measure the fuzzy probabilities of the BEs and the PEs which are defined in linguistic variables rather than numerical values. Afterwards, fuzzy arithmetic operations are applied to conduct quantitative FTA and ETA. 


\section{A hybrid framework to evaluate change formation and implementation processes}

In this section, we introduce a hybrid framework that combines FTA, ETA and fuzzy logic methods to evaluate the change formation and change implementation processes. In order to analyse the risk of change, both the probability and the impact of a change must be predicted (Ibrahim A. Motawa et al., 2006). Moreover, identifying the events that lead to a change and also the consequences that a change request can bring, are essential for an effective proactive change management. The proposed hybrid framework employs FTA and ETA techniques to predict the probability and the impact of change respectively. FTA technique also provides information on change root causes and helps with understanding a change formation process. On the other hand, ETA method helps with tracking change consequences and how it can lead to undesired outcomes. This comprehensive approach helps the project team to address change root causes to reduce change probability and also enables them to predict and deal with change impacts. Thus the project team can develop more effective risk response strategies for the potential change. Fig. 3 illustrates the stages of the framework development that are explained in further detail below. 


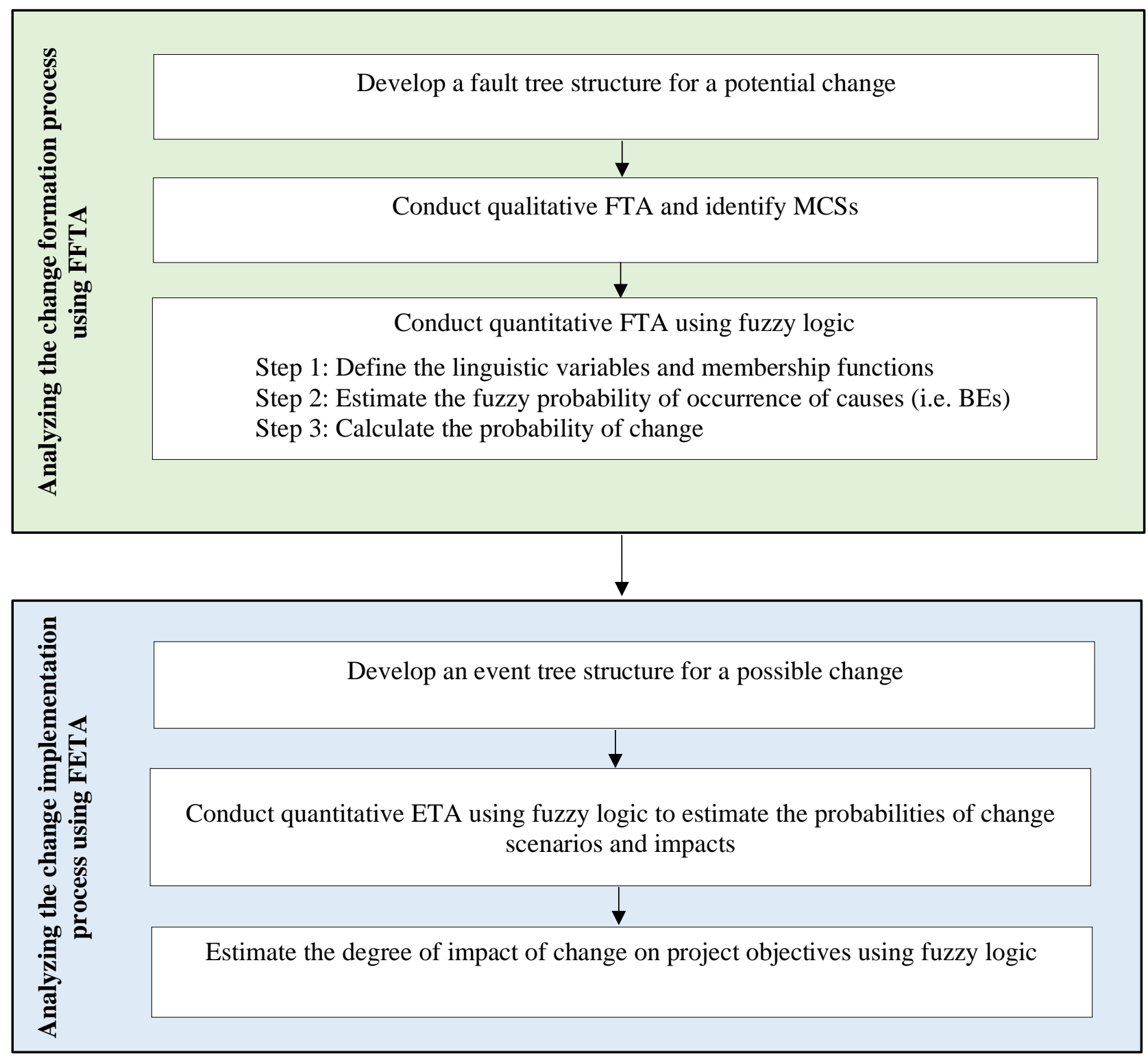

Fig. 3. Overview of the proposed framework 


\section{Analyzing the change formation process using FFTA}

\section{Develop a fault tree structure for a potential change}

In this step, project management teams use their expert judgment to predict a potential change and establish a fault tree structure for that specific change. Following this the root causes of the potential change, which is the TE, are identified and interconnected by OR/AND gates based on their logical relationships to form a fault tree. Potential changes can be identified and predicted by reviewing project documents including contracts, reports, baselines, management plans. Based on the project documents, project experts can identify change sources and potential changes. Change sources are the conditions and characteristics of a project that create a change, such as project location, characteristics of project parties, project-delivery system and contract arrangements, characteristics of the contractor's company (Heravi \& Charkhakan, 2014).

\section{Qualitative FTA}

Having the fault tree and the logical relations between BEs, a qualitative FTA can be employed to identify the MCSs of the potential change using Boolean algebra rules. The MCSs represent the TE in terms of its root causes and reveals different ways in which a change may occur. MCSs will then be used to quantify the possibility of the change occurrence.

\section{Estimation of the fuzzy probability of change}

To have a better understanding of the probability of occurrence of the understudy change (i.e. $P(T E)$ ), we will conduct a quantitative FTA. Here to incorporate fuzzy logics, we are following three steps which are inspired by the method discussed in in the studies conducted by Abdelgawad and Fayek (2011) and Abad et al. (2019). 


\section{Step 1: Define the linguistic variables and their membership functions}

Quantitative FTA requires the estimation of the probability of occurrence of MCS events. Not having the exact information, linguistic variables can be used and translate to fuzzy numbers to present the possibility of occurrence and the degree of uncertainty involved in each estimation. Linguistic variables are natural language terms adopted to explain an uncertain value. Inputs from experts are used to determine linguistic variables and their associated fuzzy numbers that can be used in expressing the occurrence possibility of the BEs.

Among different type of available fuzzy numbers, trapezoidal ones are easier to understand and simpler for operation, for that reason this study uses trapezoidal fuzzy numbers to define the range of linguistic variables. A trapezoidal fuzzy number $(\tilde{A})$ represented by four values as $(a, b$, $c, d)$, where all the values between $a$ and $d$ have a degree of possibility and values between $b$ and $c$ are the most likely values.

\section{Step 2: Estimate the fuzzy probability of occurrence of causes of change}

After the identification of linguistic variables that can be used, in this step a linguistic variable is assigned to each BE showing the fuzzy probability of the BE occurrence (i.e. $\boldsymbol{F P}(\boldsymbol{B E})$ ).

\section{Step 3: Calculate the probability of change}

When the fuzzy probability of the causes of change are defined, fuzzy arithmetic operations are performed to calculate the fuzzy probability of the change occurrence (i.e. $F P(T E)$ ). To convert OR and AND gates to fuzzy gates, the $\alpha$-cut principle is used. The $\alpha$-cut of a fuzzy set $A$, is a crisp set that the membership degree of any element in the set is greater than or equal to the specified value of $\alpha$. 
Based on probability theory and fuzzy arithmetic operations, for trapezoidal fuzzy numbers, the $\alpha$-cut of the $F P(T E)$ connected by an OR gate is obtained by employing Eq.5 (NASA, 2002;

Singer, 1990; Verma, Verma, Srividya, \& Gaonkar, 2007)

$$
F P(T E)^{\alpha}=\left\{1-\prod_{i=1}^{n}\left[1-\left(a_{i}+\left(\left(b_{i}-a_{i}\right) \alpha\right)\right)\right] .1-\prod_{i=1}^{n}\left[1-\left(d_{i}-\left(\left(d_{i}-c_{i}\right) \alpha\right)\right)\right]\right\}
$$

Similarly, the $\alpha$-cut of the $F P(T E)$ connected by an AND gate are obtained by employing Eq.6 (NASA, 2002; Singer, 1990; Verma et al., 2007):

$$
F P(T E)^{\alpha}=\left\{\prod_{i=1}^{n}\left[a_{i}+\left(\left(b_{i}-a_{i}\right) \alpha\right)\right] \cdot \prod_{i=1}^{n}\left[d_{i}-\left(\left(d_{i}-c_{i}\right) \alpha\right)\right]\right\}
$$

Where i refers to the BEs in the MCS and $\mathrm{n}$ is the number of BEs in the MCS. a, b, c and d refer to four elements of the trapezoidal fuzzy number related to $\mathrm{FP}(\mathrm{BE})$. By substituting $\mathrm{FP}(\mathrm{BEs})$ into Eq. 5 and 6 for different $\alpha$-cuts within interval $[0,1]$, the FP(TE) can be obtained.

The multiplication operator, $\Pi$, in Eqs. 5 and 6 can be defined as follows:

For fuzzy numbers $\widetilde{A}$ and $\widetilde{B}, \alpha$-cuts can be represented by $\boldsymbol{A}^{\alpha}=\left[\boldsymbol{a}_{\mathbf{1}} \cdot \boldsymbol{d}_{\mathbf{1}}\right]$ and $\boldsymbol{B}^{\boldsymbol{\alpha}}=\left[\boldsymbol{a}_{\mathbf{2}} \cdot \boldsymbol{d}_{\mathbf{2}}\right]$. Then $\boldsymbol{A}^{\boldsymbol{\alpha}} \times \boldsymbol{B}^{\boldsymbol{\alpha}}$ is defined as shown in Eq. 7 (Verma et al., 2007):

$$
A^{\alpha} \times B^{\alpha}=\left[\operatorname { m i n } ( a _ { 1 } \times a _ { 2 } \cdot a _ { 1 } \times d _ { 2 } \cdot d _ { 1 } \times a _ { 2 } \cdot d _ { 1 } \times d _ { 2 } ) \cdot \operatorname { m a x } \left(a_{1} \times a_{2} \cdot a_{1} \times d_{2} \cdot d_{1} \times a_{2} \cdot d_{1}\right.\right.
$$

After the calculation of $F P(T E)$, we employed the Mean of Maximum (MoM) defuzzification method to obtain the crisp value of probability of the TE (P (TE)). In this method, the defuzzified value is the average of all elements in fuzzy set $\widetilde{\boldsymbol{A}}$ with the highest membership degree. The crisp value of a trapezoidal fuzzy number $\left(\boldsymbol{a}_{\boldsymbol{i}}, \boldsymbol{b}_{\boldsymbol{i}} \cdot \boldsymbol{c}_{\boldsymbol{i}} \cdot \boldsymbol{d}_{\boldsymbol{i}}\right)$ can be calculated as shown in Eq. 8:

$$
y=\frac{b_{i}+c_{i}}{2}
$$

where $y$ is the mean of maximum, and $b_{i}$ and $c_{i}$ are the elements of the trapezoidal fuzzy number at which the membership degree is 1 . 


\section{Analyzing change implementation process using FETA}

\section{Develop an event tree structure for a potential change}

In this step, an event tree structure for possible consequences of change must be developed. Based on expert's knowledge and experience, the consequences of a potential change are predicted and different change scenarios (CSs) (i.e. event tree's paths) are identified. The event tree analyze continues until reaching the final outcomes of the change event, which often are the impact of change on project time, cost and quality objectives. The developed structure of the event tee provides a comprehensive understanding of change implementation process and how it can eventually lead to delay, cost overrun and quality degradation.

\section{Conduct quantitative ETA to estimate the probability of change scenarios}

To assess the probability of occurrence of CSs (P(CS)), first, fuzzy probability of the PEs (i.e. $\boldsymbol{F P}(\boldsymbol{P E})$ ) must be defined by selecting one of the linguistic variables. The fuzzy probability of $\mathrm{PE}_{0}$, which is a probable change, is obtained in previous steps by conducting FFTA. Based on probability theory, the probability of occurrence of each path is the intersection of probabilities of PEs located on the path. In other words, the probability of occurrence of each change scenario (i.e. $\boldsymbol{P}(\boldsymbol{C S})$ ) is calculated by multiplying the probability of PEs located on each event tree path. Thus, using fuzzy arithmetic operations and $\alpha$-cut principle, Eq. 9 is employed to calculate the fuzzy probability of each CS (FP(CS)) (NASA, 2002; Singer, 1990; Verma et al., 2007).

$$
\mathrm{FP}(\mathrm{CS})^{\alpha}=\left\{\prod_{\mathrm{i}=1}^{\mathrm{n}}\left[\left(\mathrm{a}_{\mathrm{i}}+\left(\left(\mathrm{b}_{\mathrm{i}}-\mathrm{a}_{\mathrm{i}}\right) \alpha\right)\right)\right] \cdot \prod_{\mathrm{i}=1}^{\mathrm{n}}\left[\mathrm{d}_{\mathrm{i}}-\left(\left(\mathrm{d}_{\mathrm{i}}-\mathrm{c}_{\mathrm{i}}\right) \alpha\right)\right]\right\}
$$


After assessing the $\mathrm{FP}(\mathrm{CS})$, the crisp value of probability of each $\mathrm{CS}(\mathrm{P}(\mathrm{CS}))$ is obtained using Eq. 8.

As several scenarios might result on same ultimate impact, the total probability of occurrence of such impact can be calculated by the summation of the probarbitals of different scenarios having this similar impact. For instance, cost overrun can be the final impact due to several senarios suvh as labors unproductivity and planning errors thus the probability of cost overrun occuerence will be the sum of all the scenarios with such impact. In this study, we are interested to find out the final impacts of an implemented change on project main objectives including time, cost and quality baseline plans. Therefore, we will classify change implementation scenarios according to their impacts on baseline plans of time, cost and quality.

\section{Estimate the degree of impact of change on project objectives}

To assess the impact of each CS (i.e. $\boldsymbol{I}(\boldsymbol{C S})$ ) experts are asked to describe the degree of change impact on project time, cost and quality objectives using linguistic variables. Then, their equivalent fuzzy numbers are defuzzified by Eq. 8. Finally, the total degree of change impact (D (CI)) on each project objective is assessed by the sum of the degree of impact of each scenario.

\section{Assess the risk of change using a risk index}

When the probabilities of occurrence and the degree of impacts of the change implementation are assessed, Change Risk Index (CRI) can be utilized as shown in Eq. 10 (Abad et al., 2019):

$$
\mathrm{CRI}=\sum \mathrm{P}(\mathrm{CI}) \times \mathrm{D}(\mathrm{CI})
$$




\section{Here $\mathrm{P}(\mathrm{CI})$ refers to ... that can be extracted from FTE or ... by... and $\mathrm{D}(\mathrm{CI})$ referes to what?}

\section{Case study}

In this section, we apply the proposed framework on a construction project to demonstrate its application in analyzing change initiation and implementation processes. The case project is a commercial-residential complex located in Tehran, Iran which includes more than 300 apartments. The same case project has been used in the study of Abad et al. (2019), in which they proposed a framework using on fuzzy FTA to evaluate different causes of change. Therefore, for the initial stage of the framework, we refer to the process and findings of Abad et al. (2019) study and further complete their findings through Stage 2 by analyzing the implementation phase and estimate the change impact on project main objectives. In Stage 3, the change will be assessed as a risk using the proposed risk index.

Interview with senior project managers of the case project resulted in recognition of the change in design as the most important sources of change in the project. Due to erroneous and incomplete design documents and also delay in design information, changes in design identified to be one of the main potential changes in this project. Changes in design has adverse effects on project performance and can lead to significant delay and budget overrun. Thus, it was important to evaluate its formation and implementation phases and predict its probability and impact.

To collect primary data, an expert task group was organized including: (1) the project manager, having 18 years of experience; (2) the technical manager, having 16 years of experience; (3) the site manager, having 22 years of experience; and (4) the engineering supervisor, having 12 years of experience. To establish the fault tree structure for design change, several interviews were 
arranged with this group of project experts to identify all causes of the change in design occurrence. The Delphi technique was used in three rounds to reach consensus among the experts on root causes (GEs and BEs) of the design change. Details of the process can be seen in Abad et al. (2019) study. The logical relationships between the root causes defined by the experts using OR or AND gates and illustrated these relations in a fault tree as shown in Fig. 4 (as reported in Abad et al. (2019)) . Table 1 shows the GEs and BEs of the tree. Thereafter, the qualitative FTA performed and 12 MCSs were yielded as shown in Eq. 11 which indicates that the occurrence of each of the BEs is enough for the change to take place.

$$
M C S S=\{B E 1\} .\{B E 2\} .\{B E 3\} \ldots . \ldots\{B E 12\}
$$

In the next step, linguistic variables and their corresponding fuzzy membership functions were defined by the group of experts with the researchers' assistance. Table 2 shows the linguistic variables and their associated fuzzy numbers that was suggested in Abad et al. (2019) and we are using them in this study as well. Then for quantitative assessment of fault tree, the expert task group described the probability of occurrence of each root causes linguistically and the fuzzy probability of the BEs were determined as represented in Table 3. By applying Eq 5. FP(TE) is calculated as fuzzy number $[0.5926,0.7807,0.9124,0.9798]$. We refer the readers to Abad et al. (2019) for a detailed estimation of FP(TE). Finally, by applying MoM defuzzification method, the $\mathrm{P}(\mathrm{TE})$ is obtained as $84.66 \%$ as shown in Eq. 12:

$$
P(T E)=\frac{0.7807+0.9124}{2}=84.66 \%
$$




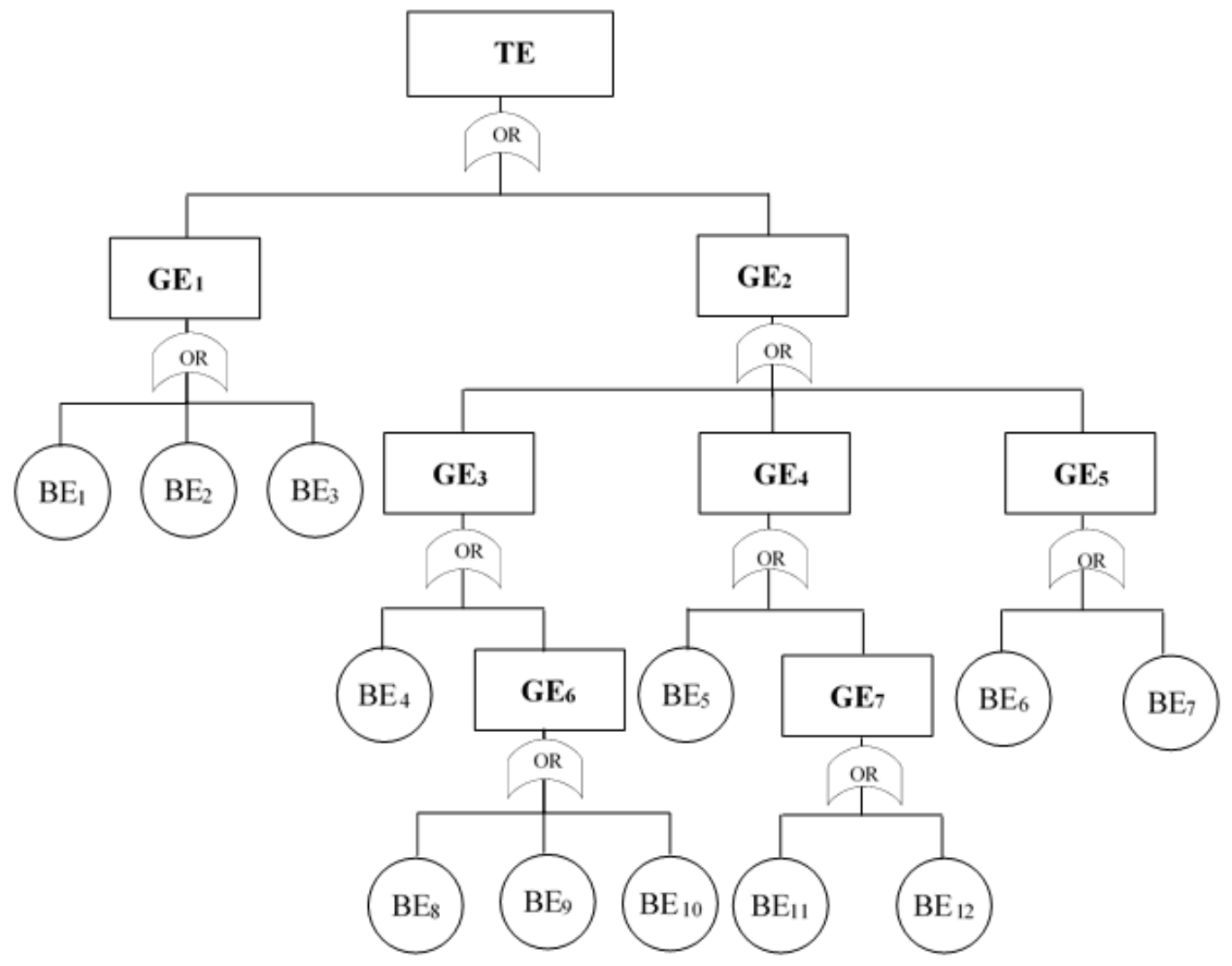

Fig. 4. Fault tree structure for the change in design [reported in (Abad et al., 2019)]

Now that we have the probability of this change occurrence $(\operatorname{FP}(\mathrm{TE}))$, this stage is to analyze the change implementation phase using ETA. The aim of this analysis is to identify the probable consequences that the change in design may contain and evaluate its impact on project main objectives, namely time, cost and quality. In this step, using checklist and Delphi technique, the expert task group is asked to identify all the main change scenarios (CSs) and pivotal events (PEs). For example, one possible CS is to be forced to complete additional work as a possible outcome of design change and it may be followed by the need for additional resources. In this 
scenario, additional work and additional resources are referred to as PEs. To complete the event tree, all the main PEs and CS should be identified. In this process, 22 CSs including 18 PEs were identified by the expert task group and the event tree structure was developed.

Afterwards, based on the expert task group's knowledge fuzzy probabilities of PEs were defined by linguistic variables as shown in Table 2 . The identified PEs and their fuzzy probability are presented in Table 4. By applying Eq. 9, FP(CS) is calculated for each CS and then converted to a crisp number using Eq. 8. For example, for CS (1) the FP(CS) is calculated as shown in Eq. 13:

$$
\begin{gathered}
F P(C S)^{\alpha}=\left[F P\left(P E_{0}\right)^{\alpha}\right] \times\left[F P(P A)^{\alpha}\right] \times\left[F P(P J)^{\alpha}\right] \\
=[(0.5926+((0.7807-0.5926) \times \alpha)) .(0.9798-((0.9798-0.9124) \times \alpha))] \\
\times[(0.01+((0.05-0.01) \times \alpha)) .(0.15-((0.15-0.1) \times \alpha))] \\
\times[(0.45+((0.6-0.45) \times \alpha)) .(1-((1-1) \times \alpha))]
\end{gathered}
$$

By increasing the value of $\alpha$ by 0.1 increments within the interval $[0,1]$, the FP(CS) for CS(1) was obtained as fuzzy number $[0.0027,0.0234,0.0912,0.1470]$. The FP (CS) is then converted to a crisp value by employing MoM defuzzification method and the probability of occurrence of CS (1) is obtained as $5.73 \%$.

The total probability of occurrence of change impacts $(\mathrm{P}(\mathrm{CI}))$ was assessed by the sum of the crisp values of the probability of occurrence of each impact. For instance, the total probability of occurrence of quality deficiency $\left(P(C I)_{\text {Quality }}\right)$ due to the design change is the summation of the crisp value of the probability of occurrence of scenarios number 8,10 and 19 as $4.52 \%$ as shown in Eq. 14.

$$
P(C I)_{\text {Quality }}=P\left(C S_{8}\right)+P\left(C S_{10}\right)+P\left(C S_{19}\right)=0.0115+0.0042+0.0295=0.0452
$$

The expert task group was also asked to express the degree of impact of change on time, cost and quality linguistically. Then, their corresponding fuzzy membership function defuzzified using 
MOM technique and the total degree of change impact $(\mathrm{D}(\mathrm{CI}))$ was obtained from the sum of the crisp numbers of the degree of change impact on time, cost and quality separately. The event tree structure for design change and its quantitative analysis is shown in Fig. 5. Finally, After the probability and impact of the change were determined, the risk index was calculated for each of the objectives as shown in Table 5 . 


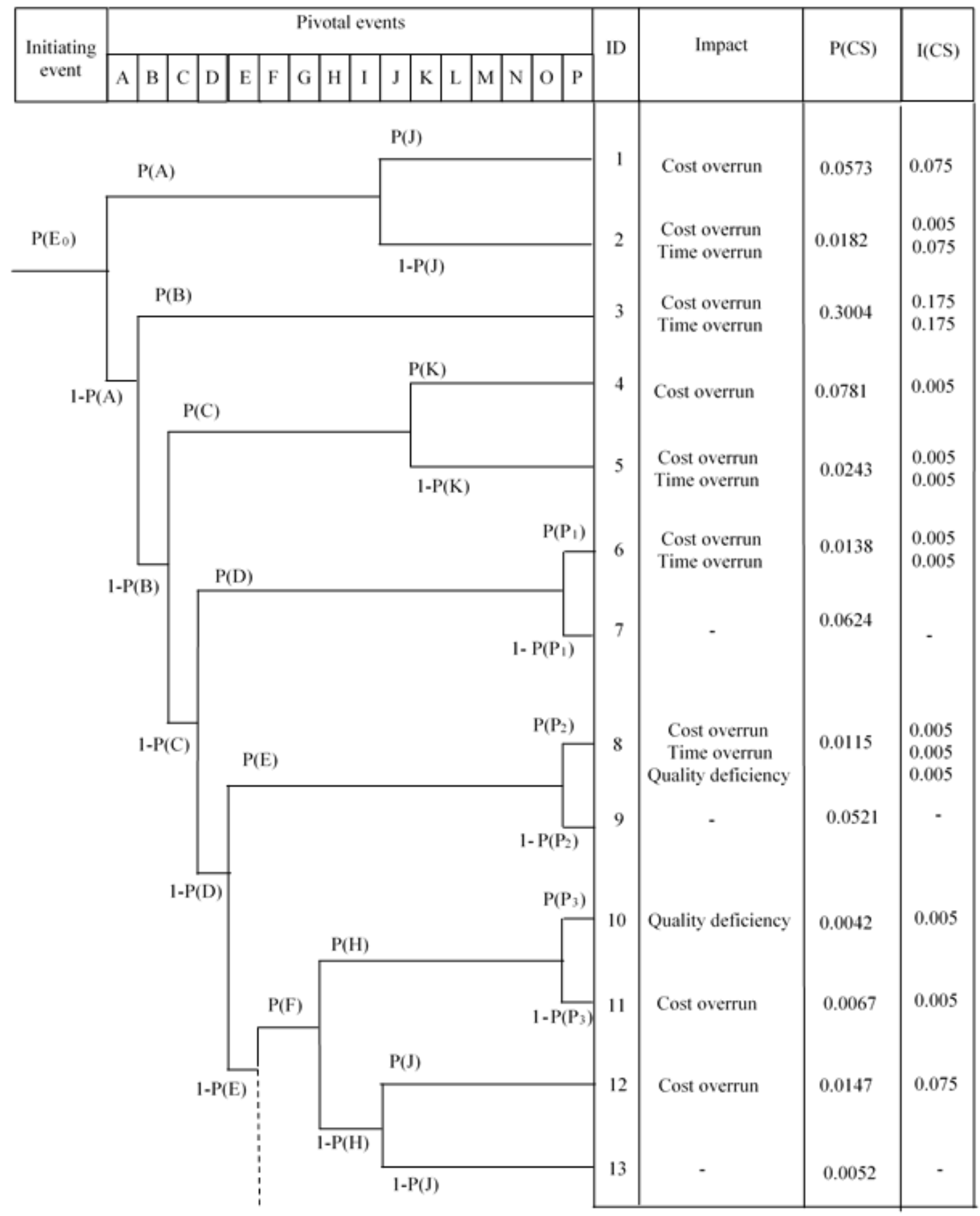




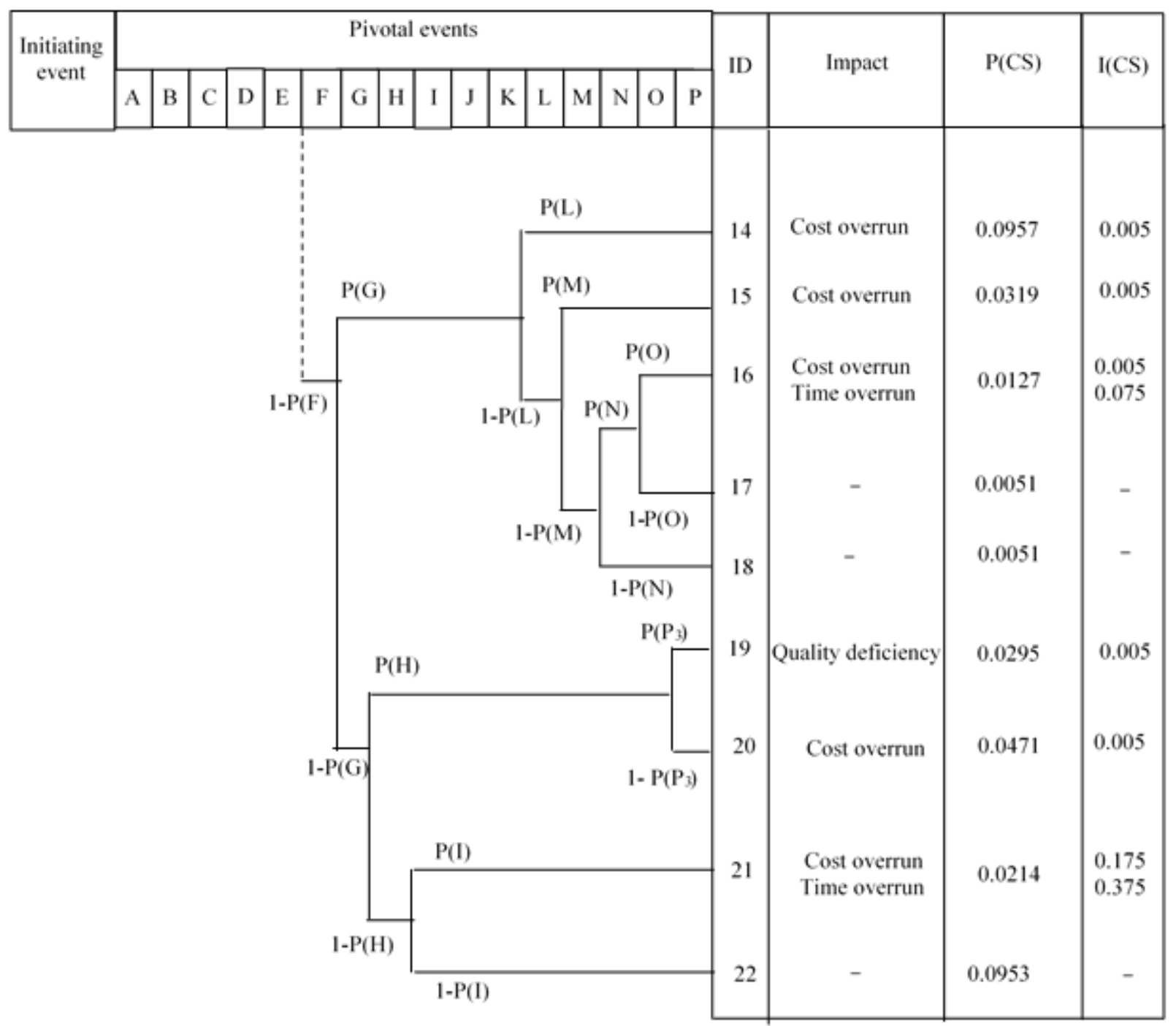

Fig. 5. The event tree structure for the design change, change scenarios probabilities and impacts

\section{Analysis and results}

The result obtained from FFTA reveals that the occurrence of each root cause contributes to change occurrence and there is a very high chance that the project will encounter the change of design. The FETA shows that if change in design happens, the third scenario of cost and time increase resulted from rework due to change in design, with a $\mathrm{P}(\mathrm{CS})$ of 0.3004 , is the most probable 
scenario. On the other hand, the least probable scenario that may arise from the change is tenth scenario of quality deficiency resulted from productivity loss due to overtime, caused by work acceleration with a $\mathrm{P}(\mathrm{CS})$ of 0.0042 .

Regarding the degree of impact, scenarios (3) and (21) with a I(CS) of 0.175 have the highest impact on project cost objectives, while scenario (21) with a I(CS) of 0.375 have the highest impact on time overrun. The degree of impact on quality with a I(CS) of 0.005 is equal for scenarios 8,10 and 19.

Furthermore, the results obtained from utilizing CRI indicate that the risk of cost overrun due to the design change implementation in the project with a CRI of 0.4036 has the highest priority. It means that in comparison with the risks of time overrun and quality deficiency, it is most important to consider proactive measures and strategies to reduce the effect of change on cost. In addition, the quality deficiency due to the change in design with a CRI of 0.0007 is the least important impact of the change.

In order to verify the validity of the results, this study utilized face validity method. The face validity is a subjective judgment of a non-statistical nature that seeks the approval of nonresearchers regarding the validity of a particular study (Leedy \& Ormrod, 2016). An interview was conducted with the same group of project experts and based on their experience and judgment they confirmed the results. The case study is selected to demonstrate the framework application. Thus, the results obtained from the case study-project belongs to this project and cannot be generalized. However, by following the steps explained in this paper, the framework can be applied to assess the risk of different type of change in other construction projects. 


\section{Conclusions}

This paper proposed a comprehensive framework to assess the risk of change in construction projects by focusing on both formation and implementation phases of change. This study uses FTA technique to understand and analyse change formation process and assess the probability of change occurrence which is inspired from (). ETA technique is used to evaluate change implementation process and identify change consequences and impacts on project objectives. This approach uses fuzzy set theory to conduct quantitative FTA and ETA and to assess the impact of change on time, cost and quality deviation. In this way, the difficulties related to lack of empirical data in construction projects can be overcome. To prioritize the risks of change, a risk index is employed that that considers the probability of occurrence and the degree of change impacts. Lastly, an example is presented to show the framework application.

The framework presented in this paper can help the project management team to observe change causes and predict change occurrence in a project. In addition, it provides an understanding about the chain of events that may result from change implementation and its final outcomes. Thus, they can prepare a risk response plan to hinder the occurrence of change or reduce its adverse effects.

Future research can be conducted using fuzzy rules to construct fault tree and event tree diagrams. Moreover, the fault tree and event tree method are unable to fully simulate the dynamic interaction between change causes and change events. Therefore, there is a need for further studies to deal with this shortcoming.

\section{References}

Abad, F., Eshtehardian, E., \& Taghizade, K. (2019). Framework for Proactive Change Management: Assessing the Risk of Change in Construction Projects Using Fuzzy Fault 
Tree Analysis. Journal of Architectural Engineering, 25(2), 04019010. doi: 10.1061/(ASCE)AE.1943-5568.0000358

Abdelgawad, M., \& Fayek, A. R. (2011). Fuzzy Reliability Analyzer: Quantitative Assessment of Risk Events in the Construction Industry Using Fuzzy Fault-Tree Analysis. JOURNAL OF CONSTRUCTION ENGINEERING AND MANAGEMENT, 137(4), 294-302.

Alaryan, A., Emadelbeltagi, Elshahat, A., \& Dawood, M. (2014). Causes and Effects of Change Orders on Construction Projects in Kuwait. International Journal of Engineering Research and Applications, 4(7), 1-8.

Alnuaimi, A. S., Taha, R. A., Mohsin, M. A., \& Al-Harthi, A. S. (2010). Causes, Effects, Benefits, and Remedies of Change Orders on Public Construction Projects in Oman. JOURNAL OF CONSTRUCTION ENGINEERING AND MANAGEMENT, 136(5), 615622.

Andrews, J. D., \& Dunnett, S. J. (2000). Event-tree analysis using binary decision diagrams. IEEE TRANSACTIONS ON RELIABILITY, 49(2), 230-238. doi: 10.1109/24.877343

Ansari, R. (2019). Dynamic Simulation Model for Project Change-Management Policies: Engineering Project Case. JOURNAL OF CONSTRUCTION ENGINEERING AND MANAGEMENT, 145(7), 05019008. doi: doi:10.1061/(ASCE)CO.1943-7862.0001664

Arain, F. M., \& Pheng, L. S. (2005). The potential effects of variation orders on institutional building projects. Facilities, 23(11/12), 496-510. doi: doi:10.1108/02632770510618462

Arain, F. M., \& Pheng, L. S. (2007). Modeling for management of variations in building projects. Engineering, Construction and Architectural Management, 14(5), 420-433. doi: doi:10.1108/09699980710780737

Charkhakan, M., \& Heravi, G. (2012). Identification of Changes Formation Scenarios in Construction Projects Based on Changes Occurrence Paths Analysis Construction Research Congress 2012 (pp. 427-436): American Society of Civil Engineers.

Cheliyan, A. S., \& Bhattacharyya, S. K. (2018). Fuzzy fault tree analysis of oil and gas leakage in subsea production systems. Journal of Ocean Engineering and Science, 3(1), 38-48. doi: https://doi.org/10.1016/j.joes.2017.11.005

Chen, J.-H. (2008). KNN based knowledge-sharing model for severe change order disputes in construction. Automation in Construction, 17(6), 773-779. doi: http://dx.doi.org/10.1016/j.autcon.2008.02.005

Enshassi, A., Arain, F., \& Al-Raee, S. (2010). Causes of variation orders in construction projects in the Gaza Strip. Journal of Civil Engineering and Management, 16(4), 540-551. doi: 10.3846/jcem.2010.60

Ericson, C. A. (1999). fault tree analysis-a history. Paper presented at the the 17th International System Safety Conference, Unionville, Virginia, USA.

Ferdous, R., Khan, F., Sadiq, R., Amyotte, P., \& Veitch, B. (2009). Handling data uncertainties in event tree analysis. Process Safety and Environmental Protection, 87(5), 283-292. doi: https://doi.org/10.1016/j.psep.2009.07.003

Hanna, A. S., Lotfallah, W. B., \& Lee, M.-J. (2002). Statistical-Fuzzy Approach to Quantify Cumulative Impact of Change Orders. JOURNAL OF COMPUTING IN CIVIL ENGINEERING, 16(4), 252-258.

Heravi, G., \& Charkhakan, M. H. (2014). Predicting and Tracing Change-Formation Scenarios in Construction Projects Using the DEMATEL Technique. JOURNAL OF MANAGEMENT IN ENGINEERING, 30(6), 04014028. doi: doi:10.1061/(ASCE)ME.1943-5479.0000229 
Heravi, G., \& Charkhakan, M. H. (2015). Predicting Change by Evaluating the Change Implementation Process in Construction Projects Using Event Tree Analysis. JOURNAL OF MANAGEMENT IN ENGINEERING, 31(5), 04014081. doi: doi:10.1061/(ASCE)ME.1943-5479.0000325

Hong, E.-S., Lee, I.-M., Shin, H.-S., Nam, S.-W., \& Kong, J.-S. (2009). Quantitative risk evaluation based on event tree analysis technique: Application to the design of shield TBM. Tunnelling and Underground Space Technology, 24(3), 269-277. doi: http://dx.doi.org/10.1016/j.tust.2008.09.004

Hwang, B.-G., \& Low, L. K. (2012). Construction project change management in Singapore: Status, importance and impact. international journal of project management, 30, 817826.

Ibbs, C. W., Wong, C. K., \& Kwak, Y. H. (2001). PROJECT CHANGE MANAGEMENT SYSTEM. JOURNAL OF MANAGEMENT IN ENGINEERING, 17(3), 159-164.

Ibbs, W., \& Chen, C. (2015). Proactive Project Change-Prediction Tool. Journal of Legal Affairs and Dispute Resolution in Engineering and Construction, 7(4), 04515003. doi: doi:10.1061/(ASCE)LA.1943-4170.0000175

Lavasani, S. M., Ramzali, N., Sabzalipour, F., \& Akyuz, E. (2015). Utilisation of Fuzzy Fault Tree Analysis (FFTA) for quantified risk analysis of leakage in abandoned oil and natural-gas wells. Ocean Engineering, 108, 729-737. doi: http://dx.doi.org/10.1016/j.oceaneng.2015.09.008

Lavasani, S. M., Zendegani, A., \& Celik, M. (2015). An extension to Fuzzy Fault Tree Analysis (FFTA) application in petrochemical process industry. Process Safety and Environmental Protection, 93, 75-88. doi: http://dx.doi.org/10.1016/j.psep.2014.05.001

Leedy, P. D., \& Ormrod, J. E. (2016). Practical Research: Planning and Design: Pearson.

Lees, F. (2005). 9 - Hazard Assessment. In S. Mannan (Ed.), Lees' Loss Prevention in the Process Industries (Third Edition) (pp. 9/1-9/123). Burlington: Butterworth-Heinemann.

Likhitruangsilp, V., Handayani Tantri, N., Ioannou Photios, G., \& Yabuki, N. (2018). A BIMEnabled System for Evaluating Impacts of Construction Change Orders.

Memon, A., Abdul Rahman, I., \& Faris Abul Hasan, M. (2014). Significant Causes and Effects of Variation Orders in Construction Projects. Research Journal of Applied Sciences, Engineering and Technology, 7, 4494-4502. doi: 10.19026/rjaset.7.826

Motawa, I. A., Anumba, C. J., \& El-Hamalawi, A. (2006). A fuzzy system for evaluating the risk of change in construction projects. Advances in Engineering Software, 37(9), 583-591. doi: http://dx.doi.org/10.1016/j.advengsoft.2006.01.006

Motawa, I. A., Anumba, C. J., Lee, S., \& Peña-Mora, F. (2007). An integrated system for change management in construction. Automation in Construction, 16(3), 368-377. doi: http://dx.doi.org/10.1016/j.autcon.2006.07.005

NASA. (2002). Fault Tree Handbook with Aerospace Applications. Washington, DC: NASA Office of Safety and Mission Assurance.

Nývlt, O., \& Rausand, M. (2012). Dependencies in event trees analyzed by Petri nets. Reliability Engineering \& System Safety, 104, 45-57. doi: https://doi.org/10.1016/j.ress.2012.03.013

Ramzali, N., Lavasani, M. R. M., \& Ghodousi, J. (2015). Safety barriers analysis of offshore drilling system by employing Fuzzy Event Tree Analysis. Safety Science, 78, 49-59. doi: https://doi.org/10.1016/j.ssci.2015.04.004

Shrestha, P. P., \& Maharjan, R. (2018). Effects of Change Orders on Cost Growth, Schedule Growth, and Construction Intensity of Large Highway Projects. Journal of Legal Affairs 
and Dispute Resolution in Engineering and Construction, 10(3), 04518012. doi: doi:10.1061/(ASCE)LA.1943-4170.0000264

Singer, D. (1990). A fuzzy set approach to fault tree and reliability analysis. Fuzzy Sets and Systems, 34(2), 145-155. doi: http://dx.doi.org/10.1016/0165-0114(90)90154-X

Sun, M., Fleming, A., Senaratne, S., Motawa, I., \& Yeoh, M. L. (2006). A Change Management Toolkit for Construction Projects. Architectural Engineering and Design Management, 2(4), 261-271. doi: 10.1080/17452007.2006.9684621

Sun, M., \& Meng, X. (2009). Taxonomy for change causes and effects in construction projects. international journal of project management, 27(6), 560-572. doi: http://dx.doi.org/10.1016/j.ijproman.2008.10.005

Verma, A. K., Verma, A. K., Srividya, A., \& Gaonkar, R. S. P. (2007). Fuzzy-reliability Engineering: Concepts and Applications: Narosa.

Wang, D., Zhang, P., \& Chen, L. (2013). Fuzzy fault tree analysis for fire and explosion of crude oil tanks. Journal of Loss Prevention in the Process Industries, 26(6), 1390-1398. doi: http://dx.doi.org/10.1016/j.jlp.2013.08.022

Wu, C.-h., Hsieh, T.-y., \& Cheng, W.-1. (2005). Statistical analysis of causes for design change in highway construction on Taiwan. international journal of project management, 23(7), 554-563. doi: http://dx.doi.org/10.1016/j.ijproman.2004.07.010

Zhao, Z. Y., Lv, Q. L., Zuo, J., \& Zillante, G. (2010). Prediction System for Change Management in Construction Project. JOURNAL OF CONSTRUCTION ENGINEERING AND MANAGEMENT, 136(6), 659-669. 